\title{
Is Late Prevention of Cerebral Palsy in Extremely Preterm Infants Plausible?
}

\author{
Benjamin A. Lear Christopher A. Lear Simerdeep K. Dhillon \\ Joanne O. Davidson Laura Bennet Alistair J. Gunn \\ The Department of Physiology, University of Auckland, Auckland, New Zealand
}

\begin{abstract}
Keywords
Periventricular white matter necrosis - Brain injury .

Cerebral palsy · Hypoxic-ischemic encephalopathy ·

Asphyxia $\cdot$ Neuroprotection
\end{abstract}

\begin{abstract}
Preterm birth continues to be associated with neurodevelopmental problems including cerebral palsy. Cystic white matter injury (WMI) is still the major neuropathology underlying cerebral palsy, affecting 1-3\% of preterm infants. Although rates have gradually fallen over time, the pathogenesis and evolution of cystic WMI are still poorly understood. Hypoxia-ischemia (HI) remains an important contributor, yet there is no established treatment to prevent injury. Clinically, serial ultrasound and magnetic resonance imaging studies typically show delayed development of cystic lesions 2-4 weeks after birth. This raises the important and unresolved question as to whether this represents slow evolution of injury occurring around the time of birth or repeated injury over many weeks after birth. There is increasing evidence that tertiary injury after $\mathrm{HI}$ can contribute to impairment of white and grey matter maturation. In the present review, we discuss preclinical evidence that severe, cystic WMI can evolve for many weeks after acute $\mathrm{HI}$ and is associated with microglia activity. This suggests the intriguing hypothesis that the tertiary phase of injury is not as subtle
\end{abstract}

karger@karger.com www.karger.com/dne

Karger $\stackrel{\text { ' }}{5}$

GOPEN ACCESS
(C) 2021 The Author(s)

Published by S. Karger AG, Basel

This is an Open Access article licensed under the Creative Commons Attribution-NonCommercial-4.0 International License (CC BY-NC) (http://www.karger.com/Services/OpenAccessLicense), applicable to the online version of the article only. Usage and distribution for commercial purposes requires written permission. as often thought and that there may be a window of therapeutic opportunity for 1 to 2 weeks after hypoxic-ischemic injury to prevent delayed cystic lesions, and so, further reduce the risk of cerebral palsy after preterm birth.

(c) 2021 The Author(s)

Published by S. Karger AG, Basel

\section{Introduction}

Preterm birth (before 37 weeks gestation) remains the leading cause of childhood death and disability [1] and represents, approximately, $10.4 \%$ of all live births, worldwide [2]. Considerable improvements in perinatal care have been associated with a gradual reduction in age-standardized mortality $[3,4]$ and an overall improvement in survival without disability in Australia of about 20\% [5]. However, in both Australia and Europe, the overall risk of cerebral palsy after preterm birth has fallen $[5,6]$, but there was no change in the risk of cerebral palsy in extremely preterm infants $(<28$ weeks gestation) [6]. Strikingly, data from the Danish Medical Birth Register, suggest that although the need for special education and risk of epilepsy declined consistently with advancing maturation, in a log-linear fashion, the risk of cerebral palsy does not fall until 29 weeks of gestation, suggesting specific maturation susceptibility [7]. 
The etiology of preterm brain injury is multifactorial, including hypoxia-ischemia (HI), infection, and barotrauma from ventilation, which alone or in combination can cause preterm brain injury [8-10]. HI may be related to events such as maternal hypotension, placenta previa and abruption, or cord obstruction $[10,11]$ and may occur before, during, or after birth [10-12]. For example, in preterm infants 5-min Apgar scores $<7$ are associated with greater risk of death or cerebral palsy compared with $\geq 9$ [13]. Similarly, clinical neonatal encephalopathy in preterm infants is more common in extremely preterm infants than at term and is associated with adverse outcomes [4].

Overall, including both term and preterm infants, intrapartum HI was estimated to be the cause of 1.15 million cases of neonatal encephalopathy in 2010 [14]. Of these, it was estimated that 287,000 infants died, 233,000 survived with moderate to severe disability, and 181,000 survived with mild disability [14]. However, it is important to note that it is difficult to estimate the precise rate of $\mathrm{HI}$ encephalopathy (HIE) in preterm infants because the clinical indices used to diagnose HIE are derived from term infants, while prematurity itself is associated with reduced spontaneous activity, tone, and suckling behavior [14]. Furthermore, due to the complex multifactorial nature of neonatal encephalopathy, there is yet to be a comprehensive proportional breakdown of the causes of neonatal encephalopathy, as the cause of death for many neonates are only listed as extreme prematurity $[4,15]$ and there is considerable evidence that preterm infants are very often exposed to infection and inflammation during the prenatal and postnatal period [16]. Regardless, there is evidence that HIE occurs in, approximately, 3537.3 per 1,000 premature live births $[4,17]$. Some small studies using very strict definitions have estimated a somewhat lower rate of HIE of 5-9 per 1,000 live births [18-20]. Similarly, among both term and preterm infants born in the UK between 2005 and 2014, sepsis after birth was reported to occur in 6.1 per 1,000 live births [21].

Pathologically, cerebral palsy is highly associated with the presence of white matter injury (WMI) on ultrasonography, with or without intraventricular hemorrhage. Although rates of cystic WMI have gradually fallen [22], cystic WMI remains highly associated with cerebral palsy $[22,23]$. For example, a recent cohort study of 889 survivors of extremely preterm birth at 10 years of age found an odds ratio of 14.3 for cerebral palsy with WMI [23]. The characteristic appearance includes cerebral echolucencies consistent with cysts and enlargement of the ventricles. Strikingly, cystic WMI is most often seen on ultrasonography at a median of $\sim 4$ weeks after birth [24]. Even relatively large cysts typically appear after a delay of several weeks after birth $[24,25]$.

The underlying mechanisms of this apparent delay before WMI appears are not known, but it could potentially reflect either late injury events after birth or slow evolution of injury. It is now well established that acute HI brain injury develops over hours to days [12]. There is growing evidence that there is a tertiary phase of ongoing inflammation and apoptosis for months after perinatal injury, and that this likely contributes to diffuse injury and dysmaturation of the developing brain [26]. In the present review, we will discuss the unknown aspects of the evolution of preterm brain injury and highlight evidence that injury during this late, tertiary phase in the extremely preterm brain may be associated with more severe brain injury than previously believed and may offer the opportunity to intervene to alleviate progression to severe disability.

\section{Cystic Injury Associated with Infection and Inflammation}

The primary focus of the present review is HI, but it is important to recognize that pathologies other than $\mathrm{HI}$ can result in cystic WMI. For many preterm infants, it is not always possible to identify the underlying cause as preterm infants present with a concoction of various injurious factors in the antenatal, perinatal, and postnatal timeframes. This is well documented in an ultrasound study comparing very preterm infants with and without WMI and demonstrates that many variables led to combinations of $\mathrm{HI}$, infection and inflammation all cumulating into the final pattern of injury [22]. In terms of infection and inflammation, the proposed mechanisms include direct injury from excessive cytokine release due to the fetal inflammatory response, placental dysfunction causing HI, maternal fever by sensitizing the brain to injury, and direct infection of the CNS [27].

Fetal inflammatory response syndrome from bacterial, viral, or fungal invasion of the amniotic sac is strongly associated with delayed neurodevelopment and WMI [28, 29]. This has been studied extensively in animal models using infusions of lipopolysaccharide, a major component of the outer membrane of gram-negative bacteria. Collectively, evidence suggests that this can trigger systemic and cerebral inflammatory responses in the form of microglial activation, astrogliosis, and excessive pro-inflammatory cytokine production [29]. Sterile sources of inflammation are also important to consider such as prolonged ventilation, which has been shown to have a cumulative effect on WMI $[12,30]$.

Perinatal viral infections can occur in utero or within days to weeks after birth [31]. Perinatal viral infections 
alone can cause significant WMI without systemic inflammation or HI, meaning the pathophysiology remains unclear $[31,32]$. To complicate matters, several viral infections have similar pattern of WMI to HI. CNS viral infections can lead to cystic lesions in the periventricular and subcortical white matter with the frontal lobe being more susceptible to injury compared to $\mathrm{HI}[31,33]$. Interestingly, delayed appearance of cystic lesions is also seen within 2 weeks of disease onset, meaning there is a possibility of overlapping mechanisms between HI and infection [31, 33]. Increased levels of inflammatory cytokines such as interleukin-6 have been reported in CSF samples from cases of rotavirus [31], suggesting that inflammation plays a key role. Furthermore, direct activation of microglia from tolllike receptors 7 and 8 by human parechovirus leads to production of reactive oxygen species and pro-inflammatory cytokines, especially tumor necrosis factor (TNF) $[33,34]$. Overall, this activation of microglia and production of TNF is highly analagous to the pathophysiology of HI brain injury, which the current review will discuss.

\section{The Evolution of Hypoxic-Ischemic Brain Injury}

The Primary Phase

The primary phase of injury corresponds to the period of HI itself. The preterm fetus has an impressive array of compensatory responses that help the fetus survive and maintain cerebral blood flow during profound hypoxia [35]. The preterm fetus is able to tolerate longer periods of hypoxia than the term fetus; however, paradoxically, this greater ability to survive prolonged exposure to profound hypoxia and hypoperfusion increases the risk of injury [35]. During HI the combination of insufficient oxygen and metabolites impairs production of adenosine triphosphate, leading to anoxic depolarization, with cell swelling (cytotoxic edema). Ultimately, this will lead to cell lysis if anoxic depolarization continues for a sufficient period $[36,37]$.

\section{The Latent Phase}

In many cases of moderate to severe HI, substantial numbers of cells are able to restore intracellular homeostasis after reperfusion, in a so-called latent phase [38]. The latent phase typically lasts around $6 \mathrm{~h}$ after HI, depending on the severity of HI [38]. The fetal EEG remains suppressed; suppression reflects a combination of neuronal dysfunction, with protective release of neuroinhibitors that mediate delayed suppression of metabolic demand with reduced cerebral blood flow [39]. There may be incomplete coupling of cerebral blood flow and metabolism with reduced intracerebral oxygenation $[12,40]$ contributing to mitochondrial dysfunction [40].
The Secondary Deterioration Phase

About $6 \mathrm{~h}$ after $\mathrm{HI}$, there is a secondary deterioration characterized by delayed onset of seizure activity, with loss of oxidative metabolism, cortical cytotoxic edema, and ultimately, extensive cell death [41]. Again, the timing and severity of the secondary phase are related in a complex manner to the severity of the primary HI; initially at least, progressively more severe $\mathrm{HI}$ is associated with earlier onset of secondary deterioration [38]. Continuing functional suppression, increased cerebral oxygenation, and loss of cytochrome oxidase in the secondary phase denote mitochondrial failure $[40,42]$. In the developing brain, cell death in this secondary phase represents a continuum between apoptosis and necrosis, with a greater proportion of necrosis in more severely affected regions [43-46].

\section{The Tertiary Phase}

Finally, there is growing evidence for a tertiary phase, involving more subtle, but important events, such as reorganization and repair, but also deleterious albeit poorly understood factors that impair brain maturation [26]. This phase may continue for months or years. For example, there is evidence that infants exposed to HI have stalled maturation of oligodendrocytes and chronic inflammation $[47,48]$ leading to impaired connectivity on MRI studies [49-51].

Modulating the immune response and the cell death pathway has been of great interest in recent animal studies, which have already shown that delayed treatment within the tertiary phase can improve outcomes days and weeks after injury [52-54]. Next, we will discuss delayed cystic lesions and argue that a preventative treatment may still be viable in the tertiary phase.

\section{Delayed Cystic Lesions}

Reinforcing the potential importance of delayed, tertiary injury, cystic or necrotic brain lesions do seem to develop over many weeks. It is important to note that cystic WMI remains one of the strongest risk factors for cerebral palsy and is seen in $1-3 \%$ of preterm born babies [55]. For example, a large serial ultrasound study in preterm infants showed that the majority of cystic lesions were not apparent soon after birth but developed late at a mean of 36 weeks post-menstrual age [25]. In another ultrasound study, cystic periventricular leukomalacia (cPVL) was identified in $2.8 \%$ in two cohorts of preterm infants born before 32 weeks [24]. Grade II cPVL developed on average 35 days after the appearance of echodensities, while grade III CPVL was seen at 21 days after the appearance of echodensities [24]. Hypothetically, this substantial delay could reflect either slow 


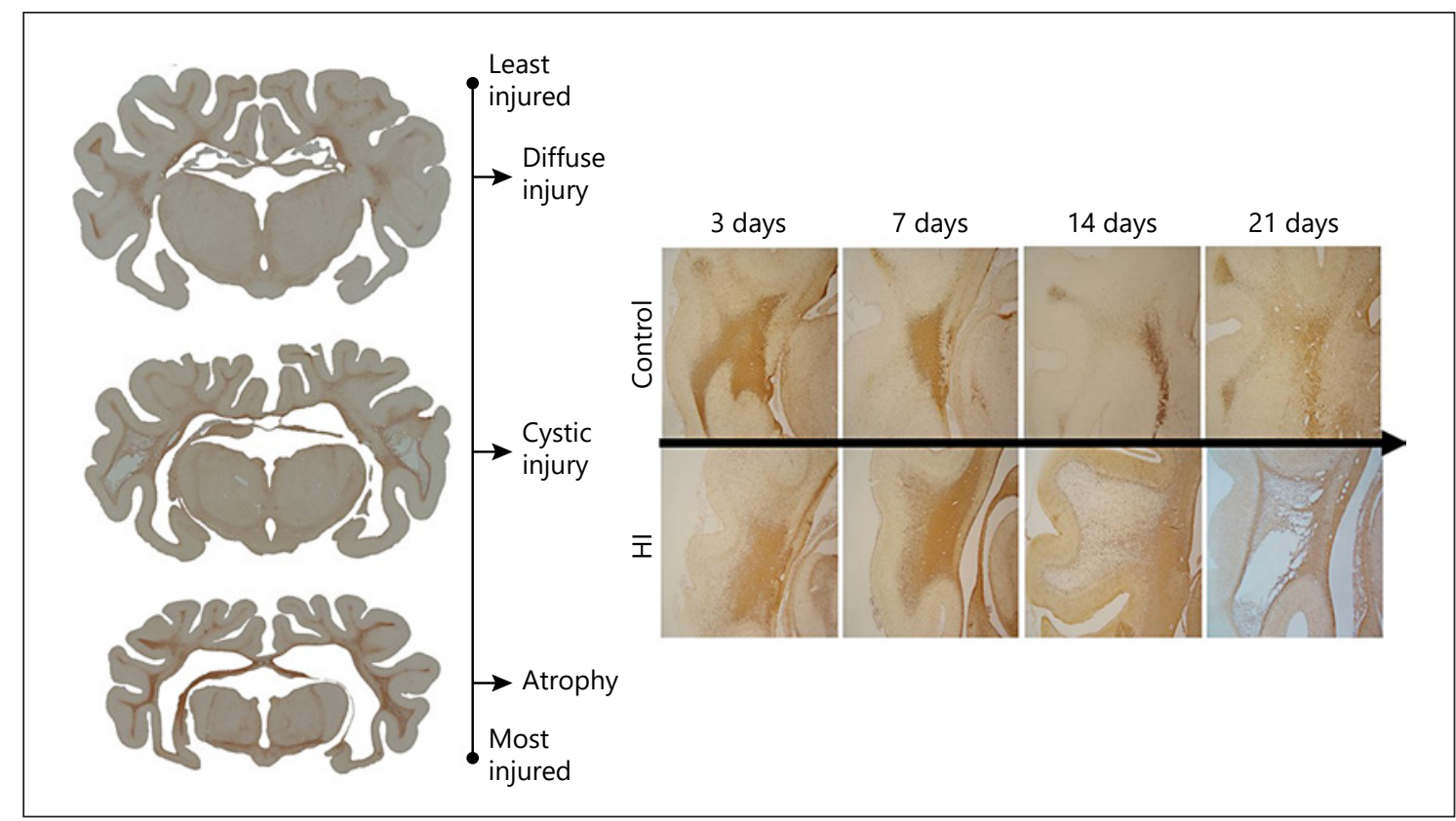

Fig. 1. The potential timeline of the evolution of cystic lesions. The coronal sections on the left demonstrate the spectrum of WMI after 21 days after HI in preterm fetal sheep: diffuse WMI (left top), cystic WMI (left middle), and white matter atrophy (left bottom). Sections on the right show the potential evolution of cystic lesions in the temporal lobe after HI induced by $25 \mathrm{~min}$ of umbilical cord occlusion (top panels show uninjured control sections, bottom panels show sections after $3,7,14$, and 21 days recovery). Note the large microglial aggregates in the 3- and 7-day HI groups, the marked dispersal of microglia in the 14-day HI group, and the cystic lesion surrounded by a gliotic barrier in the 21-day HI group. All sections are stained for Ibal positive microglia. Image adapted from Lear et al. [60], doi: 10.1093/braincomms/fcab024. evolution of injury after birth, or delayed postnatal injurious events or some combination.

There is some evidence on the timing of injurious events from serial EEG recordings. These EEG studies support the concept that EEG abnormalities are most often closely related to birth, and that, although both prenatal and postnatal injury occur, they are less common [56, 57]. A postpartum pattern was seen in $23 \%$ of preterm infants, a chronic pattern consistent with antenatal injury in $19.2 \%$, while $53.8 \%$ of cases were consistent with injury around the time of birth [56]. Consistent with this, a study of the relationship between date of cyst formation and timing of injury, found a perinatal timing of injury in 27 of 33 preterm infants, with a range of time before cyst formation of 10-39 days (median 18 days). The earliest onset was associated with the most severe cystic WMI [57].

Further, there is growing evidence from animal studies that at least in some settings cystic WMI can develop in the tertiary phase after a single episode of HI. For example, in neonatal rodent studies, necrotic brain lesions were found to evolve from $24 \mathrm{~h}$ to 21 days after $\mathrm{HI}$ induced by unilateral carotid artery ligation and inhalation- al hypoxia [58]. The timing of evolution was inversely related to the duration of the initial HI. In postnatal day (P)7 rats, severe HI was associated with cystic cerebral infarction after 2 weeks with no further change at 4 and 8 weeks [59]. By contrast, after a moderate period of HI, there was no significant infarction at 2 weeks, but extensive cortical infarction was present by 8 weeks and of comparable extent to the severe HI group [59].

These results have been supported by a recent study in preterm fetal sheep that showed delayed cystic lesion development at 21 days after global $\mathrm{HI}$ induced by complete occlusion of the umbilical cord for $25 \mathrm{~min}$ [60]. Macroscopically, the brains were relatively intact at 3 and 7 days post-HI (Fig. 1). Microscopically, the white matter showed diffuse injury, characterized by selective cellular loss of mature oligodendrocytes, increased numbers of microglia, and impaired myelination, similar to the typical pattern of diffuse noncystic WMI in contemporary human postmortem studies $[61,62]$. Interestingly, between 14 and 21 days post-HI widespread tertiary cell loss developed, with cystic lesions mainly in the temporal white matter, white matter atrophy, and ventriculomeg- 


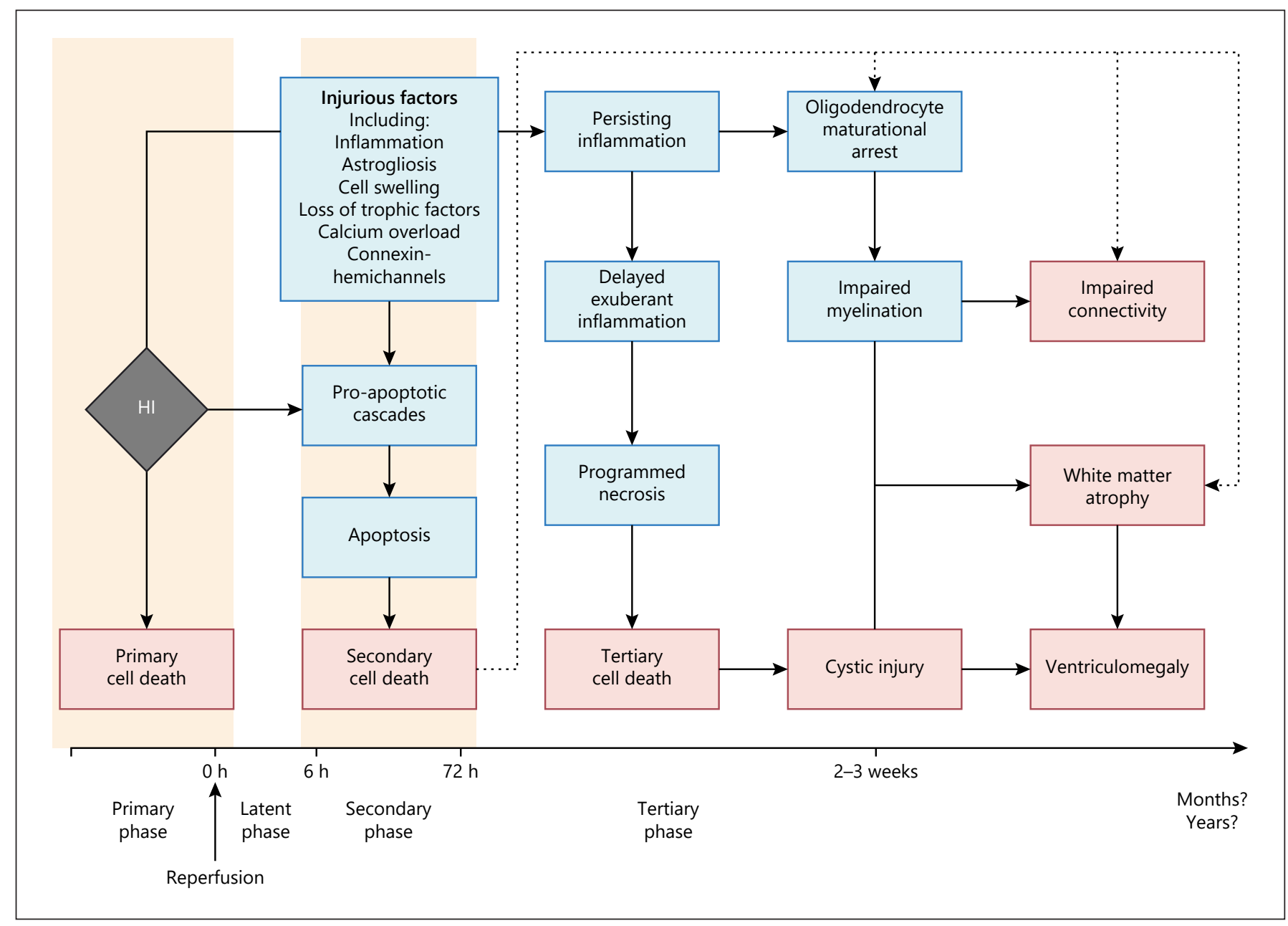

Fig. 2. Schematic drawing of the factors contributing to preterm brain injury. Diagram displaying the potential pathways and mechanisms, which may contribute to the final pattern of injury after HI. Factors along the top may interact or augment with the cell death pathways along the bottom. Both diffuse and cystic WMI are inherently linked by the same injurious factors.

aly [60]. This timing is consistent with the timeline for severe WMI injury in clinical studies [24, 63]. It is highly likely that clinical preterm brain injury is multifactorial and may be associated with combined insults. Combined insults are known to either sensitize the brain for further injury or create tolerance and so reduce subsequent injury. Overall, this concept is known as the multiple hit hypothesis [16]. It is still unclear what insults create sensitivity in human preterm infants, and even less is known about the contribution of such combined insults to cystic lesions. It is well established that inflammation is an important risk factor in sensitizing the brain to injury, as seen in the association of chorioamnionitis with cerebral palsy in term and near-term infants $[64,65]$. This increased risk of cerebral palsy may be partly related to the association between maternal fever and $\operatorname{HIE}[65,66]$. Persistent acidosis caused by chorioamnionitis in infants with HIE has also been linked to worse outcomes [67]. In a cohort of 529 preterm infants, histological chorioamnionitis was associated with greater prevalence of intraventricular hemorrhage, with an overall 2.5 -fold increased odds of developing cerebral palsy [27].

In addition, chronic hypoxia seen in fetal growth restriction may also be an important factor in sensitizing the brain to injury as fetal growth restriction is a wellestablished risk factor to hyperglycemia, pulmonary hemorrhage, stillbirth, and intrapartum asphyxia [68, 69]. For instance, in a cohort of children born before 28 weeks, a combination of small for gestational age with increased systemic inflammation considerably increased 
the risk of very low Bayley's mental development indices compared to small for gestational age or increased systemic inflammation alone [70].

\section{What Is the Mechanism of Cystic Lesions Developing} in the Tertiary Phase?

Cell death in the earlier phases shows both necrotic and apoptotic components. By contrast, intriguingly, it appears that the main route of cell death during the tertiary phase is programmed necrosis (Fig. 2) [58, 71, 72]. This is consistent with the finding of a lack of caspasepositive apoptosis at 14 and 21 days post-HI at the site of developing cystic lesions in preterm fetal sheep [60]. In neonatal rats using MRI, the number of apoptotic cells peaked at 3 days post-HI, before reducing, while cystic injury continued to develop throughout 21 days [73]. And finally, Chavez-Valdez et al. observed that many cells that survived HI presented with necrotic features [74]. Overall, these studies suggest the main pathological mechanism leading to cystic lesions is necrosis, and specifically programmed necrosis as the biochemical cascades leading to this delayed cell death may be initiated during the period of HI before taking roughly 14-21 days to propagate and cause cell death. Necrosis has been shown to be a programmable event similar to apoptosis due to the similarities in signaling cascades [75].

\section{The Biochemical Cascade}

During the early phases of HI injury, we must consider whether the toxic environment in the brain may be the key initiator of programmed necrosis. Chronic inflammation is well accepted to be a crucial component to the etiology of WMI and a key feature of the tertiary phase $[48,76]$. Elevated levels of cytokines in blood from preterm babies were shown to be strongly associated with WMI [77]. The Extremely Low Gestational Age Newborns study showed that cerebral palsy was associated with elevated inflammation-related proteins in the first two postnatal weeks [78]. Furthermore, the major proinflammatory cytokine TNF has been shown to be elevated in a cohort of children with cerebral palsy, with higher levels of TNF seen in younger children [79].

The major source of pro-inflammatory cytokines, especially TNF, is from microglia. Microglial activation is an early event after HI, and unsurprisingly, an increase in microglial number is seen in WMI [60]. An increase in microglial number and activation is associated with an increase in pro-inflammatory cytokines, such as TNF, as well as WMI in human neonates $[80,81]$. In preterm fetal sheep, we observed cystic lesions at 21 days after asphyx- ia that were preceded in the same regions by intense inflammation and a densely packed aggregate of amoeboid microglia suggesting a delayed exacerbation of neuroinflammation may have been a critical mediator in triggering tertiary cell death and macroscopic WMI [60].

Critically, the surrounding area of a cystic lesion shows increased expression of TNF and an accumulation of microglia, macrophages, and natural killer cells [76]. Programmed necrosis is initiated by the activation of membrane-bound death receptors via TNF family cytokines [82]. In brief, death receptor activation leads to deubiquintination of receptor interacting protein kinase 1 (RIP1) and 3 (RIP3), allowing RIP1 and RIP3 to form a necrosome and activate mixed lineage kinase domain-like pseudokinase. Mixed lineage kinase domain-like pseudokinase forms pores within cell and organelle membranes, leading to permeabilization and leakage of cellular contents and damage associated molecular patterns, eventual cellular lysis, and necrotic death [83]. When necrostatin-1, an inhibitor of programmed necrosis, was administered 15 min after $\mathrm{HI}$ in $\mathrm{P} 8$ mice, there was no change in acute injury within the first $24 \mathrm{~h}$, but a marked reduction in delayed injury at P11 and P28 was observed [84]. These findings illustrate that delayed tertiary injury is related to programmed necrosis initiated either during $\mathrm{HI}$, or during the acute phases of injury, but take several days or weeks to occur, resulting in a spectrum of WMI.

\section{Unknown Aspects of the Tertiary Phase}

It is yet unknown when cells commit to delayed tertiary cell death, or indeed whether delayed intervention is possible. Furthermore, knowing when cells commit to death, pathways could lead to identifying crucial biomarkers to detect at-risk infants. These aspects are important as the delayed nature of programmed necrosis suggest that substantial white matter protection may still be possible with even very delayed interventions. It is likely that an intervention targeting inflammation may be a powerful therapeutic option to treat preterm brain injury as reviewed by Davidson et al. [85].

Another important consideration is that the antecedents of cystic lesions, white matter atrophy, and/or ventriculomegaly remain unclear. Ultrasound studies report that ventriculomegaly may originate from cystic lesions collapsing upon themselves, leaving space for the ventricles to expand into $[63,86]$. Considering this, it is plausible that the occurrence of white matter atrophy may reflect previous extensive white matter cystic lesions, which evolved more quickly before collapsing. This pattern has been noted in human serial ultrasound studies [25, 87]. 
For example, Pierrat, et al. observed ventriculomegaly after the disappearance of cystic lesions in 15/78 preterm babies, while another 21/79 developed ventriculomegaly with still visible cysts [87]. These studies demonstrate the value of continuous monitoring of at-risk infants for these transient lesions as well as the eventual evolution of white matter atrophy and ventriculomegaly.

Finally, the factors governing the spatial localization of cystic lesions need to be investigated. Preexisting conditions could be present during the time of the insult, which then predispose the area to injury. As alluded to in the previous section, the eventual localization of cystic lesions at 21 days post-HI in preterm sheep was spatially associated with microglia aggregates at 3 days post- $\mathrm{HI}$ in the regions that went on to develop necrotic injury [60]. These microglial aggregates are transient structures containing large numbers of densely packed amoeboid microglia and are found in different white matter areas at different stages of development. These have been found in human postmortem studies at 19-24 gestational weeks and appear to move in parallel with the developing white matter tracts $[88,89]$. By 30-35 gestational weeks, these clusters of microglia decrease in density as microglia migrate outwards to the parenchyma [88]. Considering the evidence discussed above that TNF is a key initiator of programmed necrosis, it is plausible that microglial aggregates become areas of intense neuroinflammation after $\mathrm{HI}$ leading to widespread activation of programmed necrosis pathways, and ultimately, the formation of cystic lesions in the immediate vicinity of the aggregate.

\section{Conclusion}

There is growing evidence that events in the tertiary phase after preterm brain HI injury can lead to severe, cystic WMI and so could promote cerebral palsy. Bio- chemical cascades started in the early phases of injury do not stop at the end of the secondary phase but continue into the tertiary phase causing profound injury, including cystic lesions, ventriculomegaly, and white matter atrophy. It is likely that a key mechanism is programmed necrosis initiated by TNF produced by excessive microglial activity. We propose that the remarkable delay before necrosis may offer the potential for late interventions to prevent or alleviate cystic WMI and so reduce the risk of cerebral palsy after extremely preterm birth.

\section{Statement of Ethics}

The authors' studies reported in this review were approved by the Auckland Animal Ethics Committee (1942).

\section{Conflict of Interest Statement}

The authors have no conflicts of interest to declare.

\section{Funding Sources}

The authors were supported by grants from the Health Research Council of New Zealand (17/601).

\section{Author Contributions}

Benjamin A. Lear, Laura Bennet, and Alistair J. Gunn conceptualized the review. Benjamin A. Lear wrote the first draft of the manuscript. All authors critically revised the manuscript and approved the final manuscript as submitted and agree to be accountable for all aspects of the work.

\section{Data Availability Statement}

It is not applicable for this study.

\section{References}

1 Vogel JP, Chawanpaiboon S, Moller AB, Watananirun $\mathrm{K}$, Bonet $\mathrm{M}$, Lumbiganon $\mathrm{P}$. The global epidemiology of preterm birth. Best Pract Res Clin Obstet Gynaecol. 2018;52:3-12.

2 Chawanpaiboon S, Vogel JP, Moller A-B, Lumbiganon P, Petzold M, Hogan D, et al. Global, regional, and national estimates of levels of preterm birth in 2014: a systematic review and modelling analysis. Lancet Glob Health. 2019;7(1):e37-46.

3 Liu L, Oza S, Hogan D, Chu Y, Perin J, Zhu J, et al. Global, regional, and national causes of under-5 mortality in 2000-15: an updated systematic analysis with implications for the Sustainable Development Goals. Lancet. 2016; 388(10063):3027-35.

4 Manuck TA, Rice MM, Bailit JL, Grobman WA, Reddy UM, Wapner RJ, et al. Preterm neonatal morbidity and mortality by gestational age: a contemporary cohort. Am J Obstet Gynecol. 2016;215(1):103.e1-4.

5 Cheong JLY, Olsen JE, Lee KJ, Spittle AJ, Opie GF, Clark M, et al. Temporal Trends in Neurodevelopmental Outcomes to 2 Years After
Extremely Preterm Birth. JAMA Pediatr. 2021;175(10):1035-42

6 Arnaud C, Ehlinger V, Delobel-Ayoub M, Klapouszczak D, Perra O, Hensey O, et al. Trends in prevalence and severity of pre/perinatal cerebral palsy among children born preterm from 2004 to 2010: a SCPE collaboration study. Front Neurol. 2021;12:624884.

7 Larsen ML, Wiingreen R, Jensen A, Rackauskaite G, Laursen B, Hansen BM, et al. The effect of gestational age on major neurodevelopmental disorders in preterm infants. Pediatr Res. 2021. 
8 Rees CM, Pierro A, Eaton S. Neurodevelopmental outcomes of neonates with medically and surgically treated necrotizing enterocolitis. Arch Dis Child Fetal Neonatal Ed. 2007; 92(3):F193-8

9 Shane AL, Stoll BJ. Neonatal sepsis: progress towards improved outcomes. J Infect. 2014; 68(Suppl 1):S24-32.

10 Ophelders D, Gussenhoven R, Klein L, Jellema RK, Westerlaken RJJ, Hütten MC, et al. Preterm brain injury, antenatal triggers, and therapeutics: Timing is key. Cells. 2020;9(8): 1871.

11 MacLennan A. A template for defining a causal relationship between acute intrapartum events and cerebral palsy: international consensus statement. International Cerebral Palsy Task Force. Aust N Z J Obstet Gynaecol. 2000;40(1):13-21.

12 Dhillon SK, Lear CA, Galinsky R, Wassink G, Davidson JO, Juul S, et al. The fetus at the tipping point: modifying the outcome of $\mathrm{fe}$ tal asphyxia. J Physiol. 2018;596(23):557192.

13 Osredkar D, Verdenik I, Gergeli AT, Gersak K, Lucovnik M. Apgar score and risk of cerebral palsy in preterm infants: a populationbased cohort study. Neuropediatrics. 2021; 52(4):310-5.

14 Lee AC, Kozuki N, Blencowe H, Vos T, Bahalim A, Darmstadt GL, et al. Intrapartumrelated neonatal encephalopathy incidence and impairment at regional and global levels for 2010 with trends from 1990. Pediatr Res. 2013;74(Suppl 1):50-72.

15 Logitharajah P, Rutherford MA, Cowan FM. Hypoxic-ischemic encephalopathy in preterm infants: antecedent factors, brain imaging, and outcome. Pediatr Res. 2009;66(2): 222-9.

16 Dammann O, Leviton A. Intermittent or sustained systemic inflammation and the preterm brain. Pediatr Res. 2014;75(3):376-80.

17 Low JA. Determining the contribution of asphyxia to brain damage in the neonate. J Obstet Gynaecol Res. 2004;30(4):276-86.

18 Salhab WA, Perlman JM. Severe fetal acidemia and subsequent neonatal encephalopathy in the larger premature infant. Pediatr Neurol. 2005;32(1):25-9.

19 Chalak LF, Rollins N, Morriss MC, Brion LP, Heyne R, Sánchez PJ. Perinatal acidosis and hypoxic-ischemic encephalopathy in preterm infants of 33 to 35 weeks' gestation. J Pediatr. 2012;160(3):388-94.

20 Gopagondanahalli KR, Li J, Fahey MC, Hunt RW, Jenkin G, Miller SL, et al. Preterm Hypoxic-Ischemic Encephalopathy. Front Pediatr. 2016;4:114.

21 Cailes B, Kortsalioudaki C, Buttery J, Pattnayak S, Greenough A, Matthes J, et al. Epidemiology of UK neonatal infections: the neonIN infection surveillance network. Arch Dis Child Fetal Neonatal Ed. 2018;103(6):F547-53.

22 Ghotra S, Vincer M, Allen VM, Khan N. A population-based study of cystic white matter injury on ultrasound in very preterm infants born over two decades in Nova Scotia, Canada. J Perinatol. 2019;39(2):269-77.

23 Campbell N, Tsai A, Reading B, Thompson M, Noel-MacDonnell J, Schwartz R, et al. Risk factors for anesthetic-related complications in pediatric patients with a newly diagnosed mediastinal mass. Paediatr Anaesth. 2021; 31(11):1234-40.

24 Pierrat V, Duquennoy C, van Haastert IC, Ernst M, Guilley N, de Vries LS. Ultrasound diagnosis and neurodevelopmental outcome of localised and extensive cystic periventricular leucomalacia. Arch Dis Child Fetal Neonatal Ed. 2001;84(3):F151-6.

25 Sarkar S, Shankaran S, Barks J, Do BT, Laptook AR, Das A, et al. Outcome of preterm infants with transient cystic periventricular leukomalacia on serial xcranial imaging up to term equivalent Age. J Pediatr. 2018;195:59_ $65 \mathrm{e} 3$.

26 Fleiss B, Gressens P. Tertiary mechanisms of brain damage: a new hope for treatment of cerebral palsy? Lancet Neurol. 2012;11(6): 556-66.

27 Soraisham AS, Trevenen C, Wood S, Singhal N, Sauve R. Histological chorioamnionitis and neurodevelopmental outcome in preterm infants. J Perinatol. 2013;33(1):70-5.

28 Gomez R, Romero R, Ghezzi F, Yoon BH, Mazor M, Berry SM. The fetal inflammatory response syndrome. Am J Obstet Gynecol. 1998;179(1):194-202.

29 Jung E, Romero R, Yeo L, Diaz-Primera R, Marin-Concha J, Para R, et al. The fetal inflammatory response syndrome: the origins of a concept, pathophysiology, diagnosis, and obstetrical implications. Semin Fetal Neonatal Med. 2020;25(4):101146.

30 Barnett ML, Tusor N, Ball G, Chew A, Falconer S, Aljabar P, et al. Exploring the multiple-hit hypothesis of preterm white matter damage using diffusion MRI. NeuroImage Clinical. 2018;17:596-606.

31 de Vries LS. Viral infections and the neonatal brain. Semin Pediatr Neurol. 2019;32:100769.

32 Amarnath C, Helen Mary T, Periakarupan A, Gopinathan K, Philson J. Neonatal parechovirus leucoencephalitis- radiological pattern mimicking hypoxic-ischemic encephalopathy. Eur J Radiol. 2016;85(2):42834.

33 Verboon-Maciolek MA, Truttmann AC, Groenendaal F, Skranes J, Døllner H, Hunt RW, et al. Development of cystic periventricular leukomalacia in newborn infants after rotavirus infection. J Pediatr. 2012;160(1):1658.e1.

34 Volpe JJ. Brain injury in premature infants: a complex amalgam of destructive and developmental disturbances. Lancet Neurol. 2009; $8(1): 110-24$.

35 Bennet L. Sex, drugs and rock and roll: tales from preterm fetal life. J Physiol. 2017;595(6): 1865-81.

36 Szydlowska K, Tymianski M. Calcium, ischemia and excitotoxicity. Cell Calcium. 2010; $47(2): 122-9$.
37 Wassink G, Gunn ER, Drury PP, Bennet L, Gunn AJ. The mechanisms and treatment of asphyxial encephalopathy. Front Neurosci. 2014;8:40.

38 Williams CE, Gunn AJ, Mallard C, Gluckman PD. Outcome after ischemia in the developing sheep brain: an electroencephalographic and histological study. Ann Neurol. 1992; 31(1):14-21.

39 Davidson JO, Dhillon SK, Wassink G, Zhou KQ, Bennet L, Gunn AJ. Endogenous neuroprotection after perinatal hypoxia-ischaemia: the resilient developing brain. J Royal Soc New Zealand. 2019;49(2):79-99.

40 Bennet L, Roelfsema V, Pathipati P, Quaedackers JS, Gunn AJ. Relationship between evolving epileptiform activity and delayed loss of mitochondrial activity after asphyxia measured by near-infrared spectroscopy in preterm fetal sheep. J Physiol. 2006;572(Pt 1): 141-54.

41 Lorek A, Takei Y, Cady EB, Wyatt JS, Penrice J, Edwards AD, et al. Delayed ("secondary") cerebral energy failure after acute hypoxia- ischemia in the newborn piglet: continuous 48 hour studies by phosphorus magnetic resonance spectroscopy. Pediatr Res. 1994;36(6): 699-706

42 Toet MC, Lemmers PM, van Schelven LJ, van Bel F. Cerebral oxygenation and electrical activity after birth asphyxia: their relation to outcome. Pediatrics. 2006;117(2):333-9.

43 Northington FJ, Ferriero DM, Flock DL, Martin LJ. Delayed neurodegeneration in neonatal rat thalamus after hypoxia-ischemia is apoptosis. J Neurosci. 2001;21(6):1931-8.

44 Northington FJ, Ferriero DM, Graham EM, Traystman RJ, Martin LJ. Early neurodegeneration after hypoxia-ischemia in neonatal rat is necrosis while delayed neuronal death is apoptosis. Neurobiol Dis. 2001;8(2):207-19.

45 Gill R, Soriano M, Blomgren K, Hagberg H, Wybrecht R, Miss MT, et al. Role of caspase- 3 activation in cerebral ischemia-induced neurodegeneration in adult and neonatal brain. J Cereb Blood Flow Metab. 2002;22(4):420-30.

46 Kichev A, Rousset CI, Baburamani AA, Levison SW, Wood TL, Gressens P, et al. Tumor necrosis factor-related apoptosis-inducing ligand (TRAIL) signaling and cell death in the immature central nervous system after hypoxia-ischemia and inflammation. J Biol Chem. 2014;289(13):9430-9.

47 Back SA. White matter injury in the preterm infant: pathology and mechanisms. Acta Neuropathol. 2017;134(3):331-49.

48 Bennet L, Dhillon S, Lear CA, van den Heuij L, King V, Dean JM, et al. Chronic inflammation and impaired development of the preterm brain. J Reprod Immunol. 2018;125:4555.

49 Huppi PS, Murphy B, Maier SE, Zientara GP Inder TE, Barnes PD, et al. Microstructural brain development after perinatal cerebral white matter injury assessed by diffusion tensor magnetic resonance imaging. Pediatrics. 2001;107(3):455-60. 
50 Ment LR, Kesler S, Vohr B, Katz KH, Baumgartner $\mathrm{H}$, Schneider $\mathrm{KC}$, et al. Longitudinal brain volume changes in preterm and term control subjects during late childhood and adolescence. Pediatrics. 2009;123(2):503-11.

51 Miller SL, Supramaniam VG, Jenkin G, Walker DW, Wallace EM. Cardiovascular responses to maternal betamethasone administration in the intrauterine growth-restricted ovine fetus. Am J Obstet Gynecol. 2009;201(6):613-8.

52 Xie C, Zhou K, Wang X, Blomgren K, Zhu C. Therapeutic benefits of delayed lithium administration in the neonatal rat after cerebral hypoxia-ischemia. PLoS One. 2014;9(9): e107192.

53 Altamentova S, Rumajogee P, Hong J, Beldick SR, Park SJ, Yee A, et al. Methylprednisolone reduces persistent post-ischemic inflammation in a rat hypoxia-ischemia model of perinatal stroke. Transl Stroke Res. 2020;11(5) 1117-36.

54 Kim BH, Jeziorek M, Kanal HD, Contu VR Dobrowolski R, Levison SW. Moderately inducing autophagy reduces tertiary brain injury after perinatal hypoxia-ischemia. Cells. $2021 ; 10(4)$

55 van Haastert IC, Groenendaal F, Uiterwaal CS, Termote JU, van der Heide-Jalving $M$, Eijsermans MJ, et al. Decreasing incidence and severity of cerebral palsy in prematurely born children. J Pediatr. 2011;159(1):86-91. e1.

56 Hayakawa F, Okumura A, Kato T, Kuno K, Watanabe K. Determination of timing of brain injury in preterm infants with periventricular leukomalacia with serial neonatal electroencephalography. Pediatrics. 1999; 104(5 Pt 1):1077-81

57 Kubota T, Okumura A, Hayakawa F, Kato T, Itomi K, Kuno K, et al. Relation between the date of cyst formation observable on ultrasonography and the timing of injury determined by serial electroencephalography in preterm infants with periventricular leukomalacia. Brain Dev. 2001;23(6):390-4.

58 Northington FJ, Chavez-Valdez R, Martin LJ. Neuronal cell death in neonatal hypoxia-ischemia. Ann Neurol. 2011;69(5):743-58

59 Geddes R, Vannucci RC, Vannucci SJ. Delayed cerebral atrophy following moderate hypoxia-ischemia in the immature rat. Dev Neurosci. 2001;23(3):180-5

60 Lear BA, Lear CA, Davidson JO, Sae-Jiw J, Lloyd JM, Gunn AJ, et al. Tertiary cystic white matter injury as a potential phenomenon after hypoxia-ischaemia in preterm fetal sheep Brain Commun. 2021;3(2):fcab024.

61 Buser JR, Maire J, Riddle A, Gong X, Nguyen T, Nelson K, et al. Arrested preoligodendrocyte maturation contributes to myelination failure in premature infants. Ann Neurol. 2012;71(1):93-109.

62 Gano D, Andersen SK, Partridge JC, Bonifacio SL, Xu D, Glidden DV, et al. Diminished white matter injury over time in a cohort of premature newborns. J Pediatr. 2015;166(1): $39-43$
63 Salas J, Tekes A, Hwang M, Northington FJ Huisman TAGM. Head ultrasound in neonatal hypoxic-ischemic injury and its Mimickers for Clinicians: a review of the patterns of injury and the evolution of findings over time. Neonatology. 2018;114(3):185-97.

64 Wu YW, Escobar GJ, Grether JK, Croen LA, Greene JD, Newman TB. Chorioamnionitis and cerebral palsy in term and near-term infants. JAMA. 2003;290(20):2677-84.

65 Parker SJ, Kuzniewicz M, Niki H, Wu YW. Antenatal and intrapartum risk factors for hypoxic-ischemic encephalopathy in a US birth cohort. J Pediatr. 2018;203:163-9.

66 Badawi N, Kurinczuk JJ, Keogh JM, Alessandri LM, O’Sullivan F, Burton PR, et al. Antepartum risk factors for newborn encephalopathy: the Western Australian case-control study. BMJ. 1998;317(7172):1549-53.

67 Johnson CT, Burd I, Raghunathan R, Northington FJ, Graham EM. Perinatal inflammation/infection and its association with correction of metabolic acidosis in hypoxicischemic encephalopathy. J Perinatol. 2016; 36(6):448-52.

68 Sharma D, Shastri S, Sharma P. Intrauterine growth restriction: antenatal and postnatal aspects. Clin Med Insights Pediatr. 2016;10: 67-83.

69 Carducci B, Bhutta ZA. Care of the growthrestricted newborn. Best Pract Res Clin Obstet Gynaecol. 2018;49:103-16.

70 Leviton A, Fichorova RN, O'Shea TM, Kuban K, Paneth N, Dammann O, et al. Two-hit model of brain damage in the very preterm newborn: small for gestational age and postnatal systemic inflammation. Pediatr Res. 2013;73(3):362-70

71 Folkerth RD. Neuropathologic substrate of cerebral palsy. J Child Neurol. 2005;20(12): 940-9.

72 Northington FJ, Zelaya ME, O'Riordan DP, Blomgren K, Flock DL, Hagberg H, et al. Failure to complete apoptosis following neonatal hypoxia-ischemia manifests as "continuum" phenotype of cell death and occurs with multiple manifestations of mitochondrial dysfunction in rodent forebrain. Neuroscience. 2007;149(4):822-33

73 Jeon TY, Kim JH, Im GH, Kim JH, Yang J, Yoo SY, et al. Hollow manganese oxide nanoparticle-enhanced MRI of hypoxic-ischaemic brain injury in the neonatal rat. $\mathrm{Br} \mathrm{J} \mathrm{Ra-}$ diol. 2016;89(1067):20150806.

74 Chavez-Valdez R, Flock DL, Martin LJ, Northington FJ. Endoplasmic reticulum pathology and stress response in neurons precede programmed necrosis after neonatal hypoxia-ischemia. Int J Dev Neurosci. 2016;48: 58-70.

75 Festjens N, Vanden Berghe T, Vandenabeele P. Necrosis, a well-orchestrated form of cell demise: signalling cascades, important mediators and concomitant immune response. Biochim Biophys Acta. 2006;1757(9-10): 1371-87.
76 Bona E, Andersson AL, Blomgren K, Gilland E, Puka-Sundvall M, Gustafson K, et al. Chemokine and inflammatory cell response to hypoxia-ischemia in immature rats. Pediatr Res. 1999;45(4 Pt 1):500-9.

77 Ellison VJ, Mocatta TJ, Winterbourn CC Darlow BA, Volpe JJ, Inder TE. The relationship of CSF and plasma cytokine levels to cerebral white matter injury in the premature newborn. Pediatr Res. 2005;57(2):282-6.

78 Kuban KC, O'Shea TM, Allred EN, Paneth N, Hirtz D, Fichorova RN, et al. Systemic inflammation and cerebral palsy risk in extremely preterm infants. J Child Neurol. 2014;29(12): 1692-8.

$79 \mathrm{Wu}$ J, Li X. Plasma tumor necrosis factor-alpha (TNF- $\alpha$ ) levels correlate with disease severity in spastic diplegia, triplegia, and quadriplegia in children with cerebral palsy. Med Sci Monit. 2015;21:3868-74.

80 Kadhim H, Tabarki B, Verellen G, De Prez C, Rona AM, Sébire G. Inflammatory cytokines in the pathogenesis of periventricular leukomalacia. Neurology. 2001;56(10):1278-84.

81 Fleiss B, Van Steenwinckel J, Bokobza C, Shearer IK, Ross-Munro E, Gressens P. Microglia-mediated neurodegeneration in perinatal brain injuries. Biomolecules. 2021; 11(1):99.

82 Thornton C, Leaw B, Mallard C, Nair S, Jinnai M, Hagberg H. Cell death in the developing brain after hypoxia-ischemia. Front Cell Neurosci. 2017;11:248.

83 Thornton C, Baburamani AA, Kichev A, Hagberg $\mathrm{H}$. Oxidative stress and endoplasmic reticulum (ER) stress in the development of neonatal hypoxic-ischaemic brain injury. Biochem Soc Trans. 2017;45(5):1067-76.

84 Northington FJ, Chavez-Valdez R, Graham EM, Razdan S, Gauda EB, Martin LJ. Necrostatin decreases oxidative damage, inflammation, and injury after neonatal HI. J Cereb Blood Flow Metab. 2011;31(1):178-89.

85 Davidson JO, Dean JM, Fraser M, Wassink G, Andelius TC, Dhillon SK, et al. Perinatal brain injury: mechanisms and therapeutic approaches. Front Biosci. 2018;23:2204-26.

86 de Vries LS, Eken P, Dubowitz LM. The spectrum of leukomalacia using cranial ultrasound. Behav Brain Res. 1992;49(1):1-6.

87 Pierrat V, Marchand-Martin L, Arnaud C, Kaminski M, Resche-Rigon M, Lebeaux C, et al. Neurodevelopmental outcome at 2 years for preterm children born at 22 to 34 weeks gestation in France in 2011: EPIPAGE-2 cohort study. BMJ. 2017;358:j3448.

88 Verney C, Pogledic I, Biran V, Adle-Biassette H, Fallet-Bianco C, Gressens P. Microglial reaction in axonal crossroads is a hallmark of noncystic periventricular white matter injury in very preterm infants. J Neuropathol Exp Neurol. 2012;71(3):251-64.

89 Pierre WC, Smith PLP, Londono I, Chemtob S, Mallard C, Lodygensky GA. Neonatal microglia: the cornerstone of brain fate. Brain Behav Immun. 2017;59:333-45. 